\title{
Quick detection of sabbles by using marquis treatment
}

\author{
Herlince Sihotang ${ }^{1 *}$, Adil Ginting ${ }^{1}$, Rikson Siburian ${ }^{1}$, Crystina Simanjuntak ${ }^{1}$ \\ ${ }^{1}$ Department of Chemistry Faculty of Math and Science, Universitas Sumatera Utara, Indonesia \\ Email: sihotangherlince@yahoo.com
}

\begin{abstract}
Methamphetamine or N-methyl-alpha-methyl phenethyl amine is a powerful central nervous system stimulant drug that has an addictive effect when consumed. The number of cases of drug abuse in Indonesia in the last year is most dominated by methamphetamine so that an accurate analysis is needed to detect these compounds. Qualitative rapid detection can be done with marquis reagents which will produce a yellowish green if it is positive for consuming methamphetamine. Student urine samples were extracted with chloroform to separate to form two layers. The top layer filtrate was tested by Marquis reagents. From the test results found no positive Methamphentamine in the urine of class XI IPA students.
\end{abstract}

Keywords: Methamphetamine, marquis reagents, drugs

\begin{abstract}
Abstrak
Metamfetamin atau $\mathrm{N}$-metil-alfa-metil fenetil amin merupakan obat stimulant sistem saraf pusat yang kuat yang memiliki efek adiksi bila dikonsumsi. Jumlah kasus penyalahgunaan obat terlarang di Indonesia dalam tahun terakhir ini paling di dominasi oleh metamfetamin sehingga dibutuhkan analisis yang akurat untuk mendeteksi senyawa tersebut. Deteksi cepat secara kualitatif dapat dilakukan dengan pereaksi marquis yang akan menghasilkan hijau kekuningan jika positif mengkonsumsi sabu-sabu. Sampel urine siswa diekstraksi dengan kloroform hingga terpisah membentuk dua lapisan. Filtrat lapisan atas diuji dengan pereaksi Marquis. Dari hasil pengujian tidak ditemukan positif Metamfentamin dalam urine Siswa kelas XI IPA.
\end{abstract}

\section{Kata kunci : Metamfetamin, pereaksi marquis, narkoba}

\section{PENDAHULUAN}

Di dalam perkembangan kehidupan masyarakat yang begitu cepat, dimana perkembangan itu selalu di ikuti dengan proses penyesuaian diri yang terjadi secara tidak seimbang. Hal ini disebabkan oleh ilmu pengetahuan dan pola pikir masyarakat yang semakin berkembang, namun kemajuan teknologi yang semakin cepat dapat memberikan dampak positif maupun negatif dengan teknologi yang canggih ,dapat dilihat perkembangan di negara lain melalui berbagai media yang telah ada. Sebagai akibat kemajuan teknologi sering menimbulkan masalah sebagai modus operandi kejahatan yang canggih. Hal tersebut merupakan tantangan bagi aparat penegak hukum untuk menciptakan penanggulangan dan pencegahan peredaran kejahatan narkotika dan obat - obatan terlarang (Darmono,2008).

Perkembangan industry obat-obatan yang semakin menigkat terkadang disalahgunakan demi mendapatkan keuntungan materil yang lebih besar, sehingga berefek pada peredaran obat -obatan secara ilegal. Obat-obatan tersebut kemudian disalahgunakan sehingga menjadi bahan yang bisa membuat gangguan pada kesehatan.. Narkotika yang selalu menimbulkan rasa kekhawatiran yang 
mendalam telah mengancam langsung masa depan penerus bangsa. Tanpa pencegahan yang serius, ancaman itu bisa berlanjut pada generasi bangsa saat ini. (Undang-undang RI No 35 Thn 2009).

Peredaran dan penyalahgunaan narkotika diawali dengan pemakaian pertama pada usia Sekolah Menengah Pertama (SMP) atau Sekolah Menengah Atas (SMA), karena tawaran, bujukan, dan tekanan seseorang atau kawan sebaya. Didorong rasa ingin tahu atau ingin mencoba, pelajar tersebut mau menerimanya, selanjutnya tidak sulit untuk menerima tawaran berikutnya. Dari pemakaian sekali, kemudian beberapa kali, akhirnya menjadi ketergantungan terhadap zat yang digunakan. Narkotika yang sering disalahgunakan dan menyebabkan ketergantungan antara lain heroin (putauw), sabu (metamfetamine), ekstasi, obat penenang dan obat tidur, ganja dan kokain (Clarke, 2004).

Kehadiran Perguruan Tinggi di SMA Swasta Nasrani Medan diharapkan memberikan solusi terhadap maraknya konsumsi narkotika khususnya jenis sabu -sabu. Solusi yang ditawarkan oleh tim pengusul pengabdian adalah deteksi cepat sabu -sabu dengan menggunakan pereaksi marquist. Dengan demikian, pihak sekolah dapat melakukan pengecekan siswa siswinya secara berkala untuk menghindari terjadinya narkotika.

\section{METODE PELAKSANAAN}

2.1 Alat

Alat-alat yang digunakan pada percobaan ini adalah Erlenmeyer, tabung reaksi, pipet tetes, gelas ukur, sample cup.

2.2 Bahan

Bahan-bahan yang digunakan pada percobaan ini adalah urine siswa siswi SMA Swasra

Nasrani 1 Medan, formaldehida, asam asetat glasial, dan asam sulfat pekat, kloroform.

2.3 Prosedur Percobaan

1. Ekstraksi Urine

Ekstraksi urine dilakukan dengan menggunakan kloroform. Setelah itu, dikocok kira- kira

20 menit sampai terbentuk dua lapisan. Lapisan paling atas diambil untuk dilakukan uji

kualitatif dengan menggunakan pereaksi Marquis.

2. Pembuatan pereaksi Marquis

Pereaksi marquist terbuat dari dua (2) reagen.

Satu tetes reagen 1: Formaldehida 37\% kedalam asam asetat glasial.

Satu tetes reagen 2: Asam sulfat pekat.

\section{HASIL DAN PEMBAHASAN}

\subsection{Uji Kualitatif Serbuk Metamfetamin dengan Pereaksi Marquis}

Sebagai perbandingnan melalui hasil uji kualitatif serbuk Metamfetamin atau N-metilalfa-metil fenetil amin dengan pereaksi Marquis diperoleh (+++++) Hitam kecoklatan. 


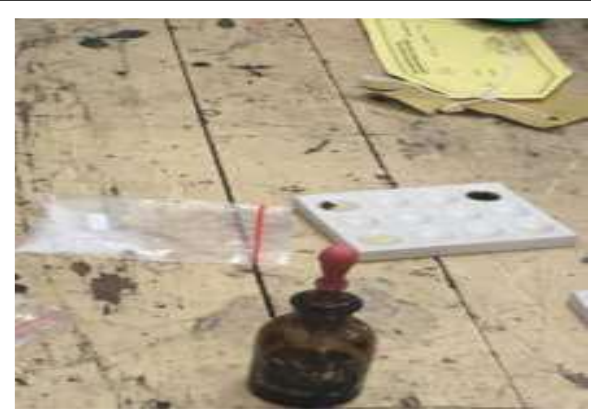

Gambar 3.1 Uji sabu-sabu dengan Pereaksi Marquis

\subsection{Uji Kualitatif Filtrat hasil ekstraksi Urine Siswa dengan Pelarut Kloroform}

Melalui hasil ekstraksi Urine Siswa dengan Pelarut Kloroform lalu dikocok selama 20 menit maka terbentuk 2 lapisan, lapisan atas di uji dengan pereaksi Marquist, pada hasil akhir diperoleh negatif Metamfetamin atau $\mathrm{N}$-metil-alfa-metil fenetil amin hasil filtrate berwarna bening dapat dilihat pada Tabel 4.1

\begin{tabular}{cl}
\hline Nama Sampel & Marquist Test \\
\hline Urine Pengguna 1 & Filtrat Bening (-) \\
Urine Pengguna 2 & Filtrat Bening (-) \\
Urine Pengguna 3 & Filtrat Bening (-) \\
Urine Pengguna 4 & Filtrat Bening (-) \\
Urine Pengguna 5 & Filtrat Bening (-) \\
Urine Pengguna 6 & Filtrat Bening (-) \\
Urine Pengguna 7 & Filtrat Bening (-) \\
Urine Pengguna 8 & Filtrat Bening (-) \\
Urine Pengguna 9 & Filtrat Bening (-) \\
Urine Pengguna 10 & Filtrat Bening (-) \\
\hline
\end{tabular}

Tabel 3.1 Uji Kualitatif Filtrat hasil ekstraksi Urine dengan Pelarut Kloroform

\subsection{Reaksi Pembentukan Warna Pereaksi Marquis dengan Metamfetamin}

Pereaksi Marquist digunakan untuk penentuan secara kualitatif senyawa aromatic seperti metamfetamin (1). Ion karbonium (2), yang dibentuk dari formaldehid, bereaksi dengan struktur aromatik dari senyawa. Dibawah pengaruh asam sulfat, ion karbenium (3) dihasilkan dan distabilkan melalui reaksi dengan molekul kedua dari komponen aromatik. Kehadiran logam berat dalam asam sulfat, seperti besi, menyebabkan oksidasi (4) ke (5). Karena media (6) asam, maka dihasilkan ion karbenium berwarna hijau kekuningan (7) yang dapat dilihat pada Gambar 3.2 dibawah ini. 


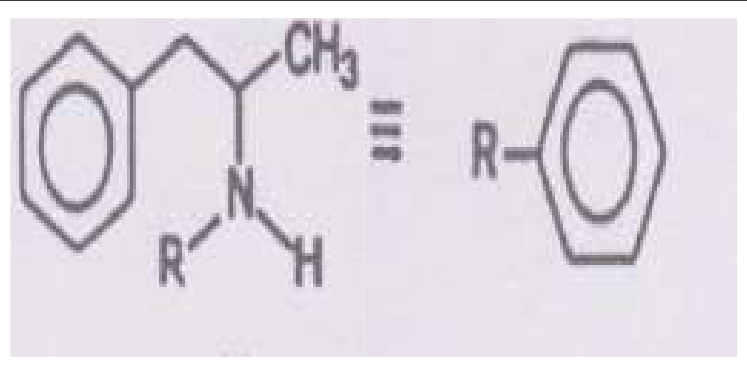

(1)

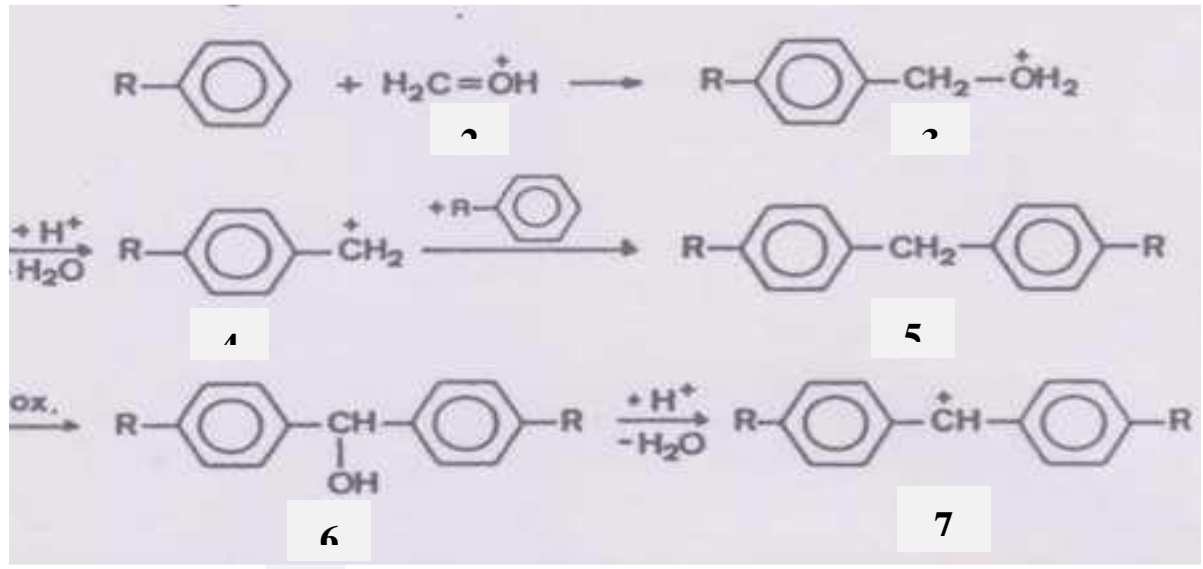

Gambar 3.2 Tahapan Pembentukan Ion Karbenium (Kenkel, 2003)

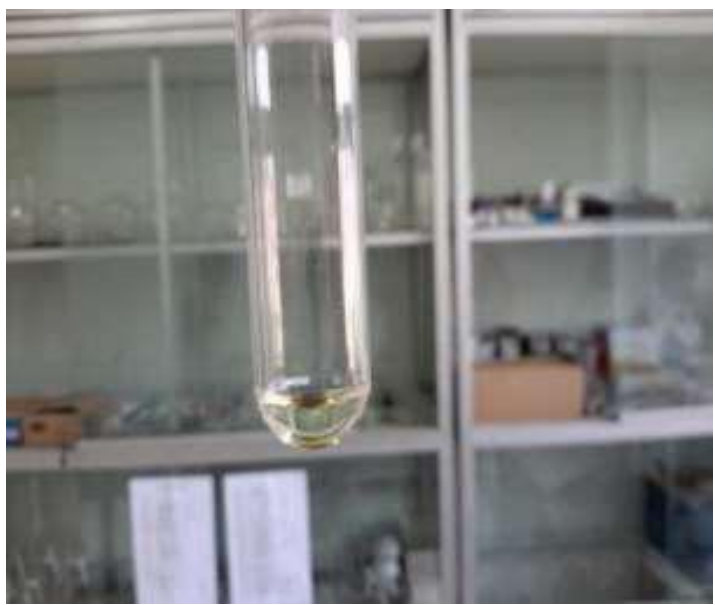

Gambar 3.3 Uji Sabu-sabu pada Urine dengan Pereaksi Marquist

\section{KESIMPULAN}

Dari hasil pengabdian pada analisis metamfetamin pada urine siswa dengan menggunakan pelarut kloroform dan pereaksi marquist tidak ditemukan adanya metamfetamin pada urine siswa. 
Herlince Sihotang et al. Quick detection

\section{UCAPAN TERIMAKASIH}

Artikel ini adalah hasil dari Program Pengabdian kepada Masyakarat yang dibiayai oleh BPPTN Universitas Sumatera Utara, sesuai dengan Surat Perjanjian Penugasan Pelaksanaan Pengabdian kepada Masyarakat Program Mono Tahun Dosen Muda, nomor: 331/UN5.2.3.2.1/PPM/2019, tanggal 20 Mei 2019. Tim Pengabdian mengucapkan terima kasih kepada Rektor dan LPPM USU atas dukungan dana dan fasilitas yang diberikan.

\section{DAFTAR PUSTAKA}

Clarke. (2004). Pharmaceutical. Third Edition. USA, Great Britain: The Bath Press

Darmono. (2008). Farmasi Forensik Dan Toksikologi. Jakarta : UI-Press

Kenkel, J. (2003). Analytical Chemistry For Technicians. America: CRC Press LLC

Undang- Undang RI No 35 Tahun 2009, Narkotika, diunduh dari website http://www.bnn.go.id/portal/_uploads/perundangan/2009/10/27/uunomor-35-tahun-2009 tentangnarkotika-ok.pdf. 